\title{
Bekering als asielmotief
}

\author{
Kezia Haar \& Gieneke Douma
}

\begin{abstract}
Behzad is geboren als moslim, derde generatie in Nederland. ${ }^{1}$ Als jongvolwassene komt hij in contact met het christelijk geloof. Hij wordt gegrepen door de warmte van de boodschap en de liefdevolle ontvangst in de gemeente. Na een periode van Bijbelstudie bekeert hij zich tot het christendom. Hij is enthousiast over wat hij heeft geleerd en ervaren. Wanneer hij kan, deelt hij zijn overtuiging en nieuwe kennis met zijn vrienden en familie. De christelijke gemeente is blij met een nieuw lid in haar midden. Iedereen leeft nog lang en gelukkig, einde verhaal.

Dit verhaal krijgt een andere lading wanneer Behzad uit Iran komt. Hij is zijn land ontvlucht vanwege politieke problemen en in Nederland terechtgekomen, alwaar hij een asielvergunning aanvraagt. Deze aanvraag wordt door de IND afgewezen, omdat de politieke problemen onvoldoende zijn om tot een asielvergunning te kunnen leiden. Zijn advocaat dient beroep in tegen dit besluit van de IND, maar de rechtbank verklaart het beroep ongegrond. Behzad moet Nederland verlaten. Maar tijdens en na zijn asielprocedure komt hij in contact met Nederlandse christenen. Hij raakt geïnteresseerd in het christendom en al vrij snel bekeert hij zich tot het christelijk geloof. Hij is enthousiast over wat hij heeft geleerd en deelt dat met zijn Iraanse kennissen en vrienden, in Nederland en Iran. Behzad vindt dat hij als christen niet meer veilig terug kan keren naar Iran. Daarom wendt hij zich opnieuw tot de IND om een asielvergunning te vragen.
\end{abstract}

Nederland heeft te maken met vreemdelingen die asiel aanvragen vanwege hun bekering in Nederland tot het christendom. De kerken waar de bekeerde vreemdelingen zich bij aansluiten, zijn zeer divers: de Nederlandse protestantse kerken, de pinkstergemeenten, de Jehova's getuigen, de doopsgezinde gemeenten en ook christelijke kerken die zich specifiek richten op vreemdelingen, zoals de Koreskerk.

De bekeerde vreemdelingen stellen niet meer terug te kunnen naar hun land van herkomst. Het ligt niet in de rede om zonder meer uit te gaan van een gestelde bekering, maar hoe kan de verantwoordelijke bewindspersoon, op dit moment de staatssecretaris van Veiligheid en Justitie (en de Immigratie- en Naturalisatiedienst (IND) namens die bewindspersoon), een innerlijke geloofsovertuiging toetsen?

In de IND-verhalenbundel Een uit duizenden verwoordt een beslismedewerker het dilemma treffend: 'Het lastige in deze zaken is dat religie iets heel persoonlijks is. Ieder mens is anders, en iedere bekeerling kan een andere invulling aan zijn

* Dit artikel is geschreven op persoonlijke titel.

1 Zowel de naam Behzad als dit verhaal is fictief, ter illustratie van het belang van het onderwerp. 
geloof geven. Toch geldt dat iemand zelf overtuigend over zijn bekering moet kunnen vertellen.'

\section{Toetsing van een asielaanvraag}

De IND is een agentschap van het ministerie van Veiligheid en Justitie. Namens de staatssecretaris van Veiligheid en Justitie voert de IND de Vreemdelingenwet en de Rijkswet op het Nederlanderschap uit. Dit betekent dat de IND alle verblijfsaanvragen beoordeelt van mensen die in Nederland willen wonen of Nederlander willen worden. ${ }^{2}$

In Nederland kan een vreemdeling onder meer een asielvergunning krijgen als hij vluchteling is. Artikel 1A van het Vluchtelingenverdrag geeft aan welke vreemdeling 'vluchteling' is. Een vluchteling is een vreemdeling die bij terugkeer naar zijn land een gegronde vrees voor vervolging heeft vanwege zijn ras, godsdienst, nationaliteit, het behoren tot een bepaalde sociale groep of zijn politieke overtuiging. Van een asielzoeker wordt verwacht dat hij aannemelijk maakt dat hij vluchteling is. De stelplicht en bewijslast liggen in beginsel bij de asielzoeker, die zover als wat in redelijkheid van hem gevraagd kan worden zijn relaas moet bewijzen. De IND heeft zelf een actieve onderzoeksplicht. Dit houdt in dat de IND een uitgebreid gehoor houdt met de vreemdeling, tijdens welk gehoor de vreemdeling zijn asielaanvraag kan toelichten. Als de vreemdeling documenten overlegt ter onderbouwing van zijn asielaanvraag, onderzoekt de IND deze documenten teneinde vast te stellen of ze authentiek zijn.

Aan de hand van het verslag van het gehoor beoordeelt de IND allereerst of het asielrelaas geloofwaardig is. In artikel 31 Vreemdelingenwet is bepaald op welke wijze de IND deze beoordeling moet verrichten, en in de Werkinstructie 2014/10 wordt uitgelegd hoe de daadwerkelijke toetsing van een asielrelaas plaatsvindt. ${ }^{3}$ Opeenvolgend worden onderzocht: de geloofwaardigheid van de relevante elementen, de aannemelijkheid van de vermoedens van de vreemdeling over wat hem bij terugkeer zal overkomen, en de zwaarwegendheid van de aannemelijke risico's over wat de vreemdeling bij terugkeer naar zijn land van herkomst zal overkomen. ${ }^{4}$

In het kader van de geloofwaardigheid wordt bekeken of de vreemdeling een relevant element kan onderbouwen. Als hij dan niet kan, wordt aan de hand van geloofwaardigheidsindicatoren getracht tot het oordeel geloofwaardig of ongeloofwaardig te komen, ${ }^{5}$ conform artikel 31 Vreemdelingenwet:

'Indien de vreemdeling zijn verklaringen of een deel van zijn verklaringen niet met documenten kan onderbouwen, worden deze verklaringen geloofwaardig

2 www.ind.nl/organisatie.

3 https://ind.nl/Documents/WI\%202014_10.pdf.

4 Paragraaf 2.3 WI 2014/10.

5 Paragraaf 3.2 WI 2014/10; geloofwaardigheidsindicatoren gebaseerd op aanknopingspunten uit art. 4 lid 5 van de Kwalificatierichtlijn, thans neergelegd in art. 31 Vreemdelingenwet. 
geacht en wordt de vreemdeling het voordeel van de twijfel gegund, wanneer aan de volgende voorwaarden is voldaan:

a. de vreemdeling heeft een oprechte inspanning geleverd om zijn aanvraag te staven;

b. alle relevante elementen waarover de vreemdeling beschikt, zijn overgelegd, en er is een bevredigende verklaring gegeven omtrent het ontbreken van andere relevante elementen;

c. de verklaringen van de vreemdeling zijn samenhangend en aannemelijk bevonden en zijn niet in strijd met beschikbare algemene en specifieke informatie die relevant is voor zijn aanvraag;

d. de vreemdeling heeft zijn aanvraag zo spoedig mogelijk ingediend, tenzij hij goede redenen kan aanvoeren waarom hij dit heeft nagelaten; en

e. vast is komen te staan dat de vreemdeling in grote lijnen als geloofwaardig kan worden beschouwd.'

De verklaringen van de vreemdeling worden getoetst op innerlijke consistentie (spreekt de vreemdeling zichzelf niet tegen?) en bijvoorbeeld ook op gedetailleerdheid. Daarnaast worden de verklaringen van de vreemdeling vergeleken met hetgeen de IND weet uit andere, objectieve bronnen (zoals ambtsberichten van de minister van Buitenlandse Zaken).

Als geconcludeerd wordt dat de verklaringen van de vreemdeling over wat hem overkomen is geloofwaardig zijn, wordt getoetst of de vrees die de vreemdeling aan zijn asielrelaas ontleent aannemelijk is en of de problemen die hij verwacht voldoende zwaarwegend zijn om een vergunning te verlenen. ${ }^{6}$

\section{Bekering als asielmotief}

Hiervoor is weergegeven hoe de geloofwaardigheid van een asielrelaas in het algemeen beoordeeld wordt. Dit uitgangspunt is hetzelfde bij toetsing van een bekering als asielmotief, met een aantal bijzondere aandachtspunten.

Bekering tot het christendom kan een grond zijn om bescherming (asiel) te verlenen, omdat de vreemdeling bij terugkeer naar zijn land problemen kan krijgen met de autoriteiten. De meeste bekeerlingen komen uit Iran, Irak en Afghanistan. Dit zijn landen waar enkel de islam de toegestane godsdienst is. Landgenoten die zich bekeren tot het christendom worden gezien als afvalligen. In een land als Iran staat hier de doodstraf op. In Irak hebben Yezidi's en christenen vooral te vrezen voor Islamitische Staat. Zij worden ontvoerd, gedood, gedwongen zich te bekeren en hun bezittingen worden vernield of geroofd. In Afghanistan wordt bekering naar een andere religie dan de islam gezien als afvalligheid. Dit is volgens de sharia strafbaar en kan leiden tot het opleggen van de doodstraf.

Net als elk ander asielrelaas wordt een gestelde bekering volgens de hiervoor genoemde tweetrap getoetst: 
a Is de bekering geloofwaardig?

b En zo ja, zijn de gevolgen van de bekering bij terugkeer naar het land van herkomst voldoende zwaarwegend om een asielvergunning te verlenen?

\section{Hoe wordt een bekering getoetst?}

De bewijslast voor het aannemelijk maken van een bekering ligt, net als bij elke andere asielaanvraag, bij de vreemdeling. Dit kan de vreemdeling doen aan de hand van zijn verklaringen en middels onderbouwende stukken (zoals een doopakte en verklaringen van geloofsgenoten). Het leveren van echt bewijs van een innerlijke geloofsbeleving is meestal niet mogelijk. De IND kan daarom doorgaans slechts aan de hand van de door de vreemdeling afgelegde verklaringen beoordelen of hij geloofwaardig acht dat de vreemdeling daadwerkelijk de gestelde geloofsovertuiging heeft.

De IND hanteert een vaste gedragslijn ter beoordeling van een door de vreemdeling gestelde geloofsovertuiging. ${ }^{7}$ Er wordt in het gehoor met de vreemdeling een vragenlijst gebruikt die tot stand is gekomen in overleg met onder meer kerkelijke instanties en met een organisatie die de belangen behartigt van christelijke asielzoekers. Er worden vragen gesteld over:

- het proces van bekering;

- algemene kennis van de inhoud van het geloof;

- indien van toepassing: kerkgang en evangelisatie-activiteiten.

Deze vaste gedragslijn laat onverlet dat er geen eenduidig sjabloon is voor het toetsen van een bekering. Er is steeds sprake van een individuele toets, aangezien bekeringen en bekeringsverhalen in verschillende soorten en maten komen. Bekeringsprocessen kunnen op uiteenlopende wijze en met uiteenlopend tempo verlopen. Naast een actieve bekering, waarbij iemand zelf op zoek is gegaan naar de waarde van het christelijke geloof voor zijn leven, kan ook sprake zijn van een passieve bekering, waarbij iemand zich - bijvoorbeeld door een droom - van hogerhand geraakt weet en daardoor van geloof verandert. ${ }^{8}$

In het geval van een bekering gaat de IND ervan uit dat sprake is van een welbewuste en weloverwogen keuze van een vreemdeling. Dit geldt nog sterker als de bekering tot een nieuw geloof of het christendom zelf in het land van herkomst maatschappelijk onacceptabel en/of strafbaar is. Daarom is de beantwoording van vragen over de motieven voor en het proces van bekering belangrijk. En of nu aan de bekering nu een langdurig proces van actief kennis vergaren voorafging, of dat sprake is van een vrij radicale snelle bekering naar aanleiding van (bijvoorbeeld) een droom, van belang is dat de vreemdeling over het proces aannemelijk, consistent en gedetailleerd verklaart.

7 Weergegeven in: ABRvS 24 mei 2013, 201109839/1/V2.

8 Zie: 'Bekering tot christus, Aandachtspunten voor de asielbeoordeling van Christenen met een achtergrond in een andere godsdienst of levensovertuiging, aandachtspunten voor de asielbeoordeling van christenen met een moslimachtergrond', www.gave.nl/gave/download/juridischextern/bekering-tot-christus-versie-3.1.pdf. 
De bekering van de vreemdeling die over het proces van bekering en de betekenis daarvan voor zijn persoonlijk leven zeer algemeen verklaarde, met summiere en vage antwoorden op concrete vragen, werd niet geloofwaardig geacht. ${ }^{9}$

Er wordt verwacht dat vreemdelingen inzicht geven in de veranderingen die het bekeringsproces bij hen teweeg hebben gebracht. De verklaring dat de vreemdeling sinds de bekering rustiger is geworden en zich beter voelt, kan onvoldoende concreet zijn. ${ }^{10}$

Ook over het proces van bekering moet consistent worden verklaard. De staatssecretaris geloofde bijvoorbeeld niet de volgende bekering. De vreemdeling stelde al jaren twijfel te hebben gehad over de islam, kreeg vervolgens een droom en was daarna plotseling en direct bekeerd tot het christendom. Hier ging geen serieuze studie van of interesse in het christelijk geloof aan vooraf. Deze gang van zaken werd niet aannemelijk geacht in relatie tot het geleidelijke proces van afvalligheid van de islam. Dat de vreemdeling enige feitelijke kennis van het geloof had, was niet voldoende om van een geloofwaardige bekering te spreken. ${ }^{11}$

\section{Waarde van overgelegde verklaringen (onder andere van kerken)}

Vreemdelingen overleggen regelmatig stukken zoals een doopakte of een verklaring van een voorganger/geestelijke die zich uitspreekt over de oprechtheid van de bekering. Een verklaring van een kerkelijke instantie of persoon kan weliswaar dienen ter staving van een bekering, maar een dergelijke verklaring doet niet af aan de verantwoordelijkheid van de betrokken vreemdeling zelf om overtuigende verklaringen af te leggen met betrekking tot zijn bekering en het proces dat tot de bekering heeft geleid. Het is vervolgens aan de staatssecretaris om zich aan de hand van de verklaringen van de betrokken vreemdeling en eventuele verklaringen van derden een oordeel te vormen over de geloofwaardigheid van de gestelde bekering. ${ }^{12}$ Voor doopaktes geldt dat deze naar hun aard geen uitsluitsel geven over de motieven voor en het proces van bekering. ${ }^{13}$

In een zaak waarin de vreemdeling in zijn mobiele telefoon moest nazoeken op welke datum hij gedoopt was, niet wist door wie en in welke kerk hij gedoopt was, niet wist welke christelijke stroming hij aanhing en wat de naam van zijn geloofsgemeenschap was, en die op de vragen over het proces voorafgaand aan de bekering volstond met de opmerking dat het een innerlijk gevoel betrof, kon de overgelegde doopakte noch de verklaring van de pinkstergemeente afdoen aan het oordeel dat de bekering niet aannemelijk was gemaakt. ${ }^{14}$

Vaste jurisprudentie van de Afdeling bestuursrechtspraak van de Raad van State $(\mathrm{ABRvS})$ is dat verklaringen van predikanten en anderen uit het maatschappelijk middenveld ${ }^{15}$ weliswaar kunnen dienen ter staving van de gestelde bekering, maar dat hieraan geen overwegende waarde kan worden toegekend, omdat het de

9 ABRvS 18 december 2014, 201407265/1/V2.

10 ABRvS 23 mei 2014, 201310780/1.

11 ABRvS 6 maart 2014, 201300914/1.

12 ABRvS 6 maart 2014, 201311217/1/V2, r.o. 4.2.

13 ABRvS 6 maart 2014, 201304031/1, r.o. 4.4.

14 ABRvS 28 oktober 2015, 201504405/1/V2.

15 Zoals de commissie-Plaisier, Stichting Gave, prof. dr. Joke van Saane. 
verantwoordelijkheid van de vreemdeling onverlet laat om tegenover de staatssecretaris overtuigende verklaringen af te leggen met betrekking tot zijn bekering en het proces dat tot die bekering heeft geleid.

\section{Herhaalde asielaanvraag}

In Nederland kan een vreemdeling na een eerdere afwijzende beslissing opnieuw een asielaanvraag indienen. Het aantal keren dat na een eerste asielaanvraag nogmaals opnieuw asiel gevraagd kan worden, is niet beperkt. In een opvolgende asielaanvraag moeten nieuwe feiten en omstandigheden worden aangedragen (nova).

Ook in zo'n herhaalde asielaanvraag kan een bekering een rol spelen. Een vreemdeling kan stellen bekeerd te zijn na een eerder ongeloofwaardig of onvoldoende zwaarwegend geacht relaas dat losstond van de nu gestelde bekering, zoals in het voorbeeld van Behzad. Maar ook als de bekering in een eerdere procedure is aangevoerd én ongeloofwaardig is geacht, kan de vreemdeling zijn bekering opnieuw aanvoeren als asielmotief.

Dan verwacht de staatssecretaris wel dat de vreemdeling aannemelijk maakt waarom de vreemdeling tot voortzetting van de bekering is gekomen, of waarom hij alsnog is bekeerd. De vreemdeling dient juist in een geval als dit inzichtelijk te maken hoe dat proces is verlopen en hiermee tot uiting te brengen dat deze keuze weloverwogen en bewust is geweest. ${ }^{16}$

Wat betreft het hanteren van de vaste gedragslijn en vragenlijst, kan het zo zijn dat de staatssecretaris zich beperkt tot het stellen van vragen over de verschillen tussen de in de opvolgende aanvraag naar voren gebrachte bekering en de reeds aan de voorafgaande aanvraag ten grondslag gelegde bekering. ${ }^{17}$

\section{Geen terughoudendheid bij uiting geloof}

Als de bekering geloofwaardig wordt geacht, mag de staatssecretaris van de vreemdeling geen terughoudendheid eisen bij de uitoefening van zijn geloofsovertuiging in het land van herkomst. ${ }^{18}$ Deze overweging komt uit het arrest van het Hof van Justitie te Luxemburg van 5 september 2012 over de zogenoemde Europese Definitierichtlijn. ${ }^{19}$ In die richtlijn zijn voor de lidstaten van de Europese Unie minimumnormen opgenomen voor bescherming van vluchtelingen. Het arrest zag op een uitspraak van de immigratiedienst van Duitsland in een zaak van een Pakistaanse vreemdeling, die het Ahmadi-geloof aanhing. De Duitse immigratiedienst had geoordeeld dat het - in het licht van de zeer zware straffen waarmee een Ahmadi bij terugkeer wordt bedreigd en de talrijke aanvallen van extremistische groepen - een zaak van gezond verstand is dat een Ahmadi zich van elke openbare belijdenis van het geloof onthoudt. Het Hof van Justitie oordeelde dat de beoordelende autoriteiten in redelijkheid niet van de asielzoeker 
mogen verwachten dat hij van de godsdienstige handelingen afziet teneinde problemen in zijn land van herkomst te voorkomen.

Indien de vreemdeling zijn bekering niet aannemelijk heeft gemaakt, heeft hij evenmin aannemelijk gemaakt dat hij bij terugkeer geloofsactiviteiten zal ontplooien. Ten aanzien van geloofsuitingen op internet (bijv. Facebook) kan van de vreemdeling worden gevergd dat hij de online geplaatste geloofsuitingen vóór terugkeer naar het land van herkomst verwijdert, en verwijderd houdt, als de gestelde bekering tot het christendom ongeloofwaardig is. ${ }^{20}$

\section{Toetsing door de bestuursrechter in eerste aanleg}

Tegen elke afwijzende beslissing op een asielaanvraag kan door de vreemdeling beroep worden ingediend bij de bestuursrechter. Tot 20 juli 2015 gold dat de rechter het oordeel van de staatssecretaris slechts terughoudend kon toetsen. De rechter stelde de vraag: is de staatssecretaris in redelijkheid tot zijn oordeel over de geloofwaardigheid kunnen komen? De rechter beoordeelde daarbij of de staatssecretaris zorgvuldig onderzoek heeft gedaan naar de gestelde bekering/ geloofsovertuiging, met andere woorden: of de vaste gedragslijn was gevolgd door de vreemdeling te bevragen over kennis, kerkgang en proces van bekering. Die toets is terughoudend te noemen, want de rechter beoordeelt niet de bekering an sich, maar de vraag of de beoordeling van de bekering door de staatssecretaris inzichtelijk en zorgvuldig is.

Op 20 juli 2015 is de Richtlijn 2013/32/EU betreffende gemeenschappelijke procedures voor de toekenning en intrekking van de internationale bescherming (Procedurerichtlijn) geïmplementeerd. De Procedurerichtlijn schrijft voor dat de rechter een volledig en ex nunc onderzoek verricht. Het ex nunc onderzoek houdt in dat alle relevante omstandigheden bij de beoordeling door de rechter worden betrokken, ook omstandigheden die zijn opgekomen nadat het bestuursorgaan een beslissing heeft genomen. Een vreemdeling kan bij de bestuursrechter dus nog aanvullende argumenten naar voren brengen, waarover de rechter zich moet uitlaten. De rechtspraak over de intensiteit van de rechterlijke toets (van enigszins terughoudend naar indringend) is nog in ontwikkeling, en de ABRvS heeft hierover op het moment van schrijven van dit artikel nog geen oordeel gegeven.

\section{Toetsing in hoger beroep door de Afdeling bestuursrecht van de Raad van State}

De Raad van State is in Nederland de hoogste rechter in het vreemdelingenrecht. De jurisprudentie van de ABRvS legt de lat voor asielzoekers die bekering als motief voor een (herhaalde) asielaanvraag aanvoeren, behoorlijk hoog. Bedacht moet echter wel worden, en dat komt ook terug in de uitspraken van de ABRvS, dat de staatssecretaris het met de verklaringen van de vreemdeling moet doen. 
Deze vormen de basis waarop de beoordeling van de geloofwaardigheid wordt verricht.

Uit de jurisprudentie van de ABRvS komt naar voren dat de zij van de vreemdeling verlangt dat hij uitgebreid verklaart over de motieven voor en het proces van bekering, teneinde de inzichtelijkheid en daarmee de controleerbaarheid van de oprechtheid van de bekering te vergroten.

In een uitspraak van 15 juli 2014 overwoog de ABRvS dat de staatssecretaris bij de motivering van het standpunt dat een bekering ongeloofwaardig is, niet alle drie de onderdelen van de gedragslijn hoeft te betrekken; het staat de staatssecretaris vrij om aan de ontoereikende verklaringen over motieven voor en het proces van bekering doorslaggevend gewicht toe te kennen: ${ }^{21}$

'De rechtbank heeft ten onrechte overwogen dat alle drie categorieën waarover de staatssecretaris in het kader van de hiervoor bedoelde vaste gedragslijn vragen pleegt te stellen, in de besluitvorming dienen terug te komen. Het staat de staatssecretaris namelijk vrij aan de motieven voor en het proces van bekering een doorslaggevend gewicht toe te kennen. De staatssecretaris is dan ook niet gehouden steeds antwoorden van de vreemdeling op vragen over de geloofsleer, geloofspraktijk en de kerkgang in de motivering van het besluit te betrekken, indien hij zich op het standpunt stelt dat, reeds gelet op de ontoereikende verklaringen van de vreemdeling over de motieven voor en het proces van bekering, aan diens antwoorden op vragen uit de andere categorieën geen gewicht toekomt.'

Terug naar Behzad. Nadat hij bij de IND had gemeld dat hij een herhaalde asielaanvraag wilde indienen, werd hij uitgenodigd voor een gehoor. Voorafgaand aan dit gehoor had zijn advocaat al enkele documenten opgestuurd naar de IND: een doopverklaring en een brief van de voorganger van zijn kerk. Tijdens het nader gehoor vertelt Behzad overtuigend en uitvoerig over het proces van zijn bekering van islam naar christendom en over het effect dat zijn bekering op hem als persoon heeft gehad. Hij geeft inzicht in de kennis die hij over zijn nieuwe geloof heeft verworven tijdens Bijbelstudie en vertelt levendig over hoe hij zijn geloof uitoefent in het dagelijks leven. Na het gehoor worden de verklaringen van Behzad door een beslismedewerker van de IND nauwkeurig bestudeerd en besproken met een collega. De beslismedewerkers zijn het gauw eens: Behzad heeft overtuigend over zijn bekering verteld, en hij heeft aangetoond een ruime kennis te hebben van de Bijbel en het christelijk geloof. Het verhaal van Behzad is daardoor voldoende aannemelijk, en hij krijgt een asielvergunning. 